\title{
Characteristics of Natural Cellulose Fibres Extracted from Sri Lankan Rice Straw Varieties
}

\author{
A. Ratnakumar ${ }^{1}$, A.M.P.B. Samarasekara ${ }^{1 *}$, D.A.S. Amarasinghe ${ }^{1}$ and L. Karunanayake ${ }^{2}$, \\ ${ }^{1}$ Department of Materials Science and Engineering, Faculty of Engineering, University of Moratuwa, Moratuwa, Sri \\ Lanka \\ ${ }^{2}$ Department of Polymer Science, Faculty of Applied Sciences, University of Sri Jayewardenepura, Nugegoda, Sri Lanka
}

\section{ARTICLE INFO}

\section{Article history:}

Received: 14 August 2019

Accepted: 23 October 2019

Revised version received: 26 May 2020

Available online: 01 July 2020

\section{Keywords:}

Cellulose fibre

Chemical treatment

Morphological analysis

Property analysis

Rice Straw

\section{Citation:}

Ratnakumar, A., Samarasekara A.M.P.B., Amarasinghe D.A.S. and Karunanayake L. (2020). Characteristics of Natural Cellulose Fibres Extracted from Sri Lankan Rice Straw Varieties. Tropical Agricultural Research, 31(3): 72-82.

DOI: http://doi.org/10.4038/tar.v31i3.8398

Ratnakumar, A.

https://orcid.org/0000-0001-7489-2732

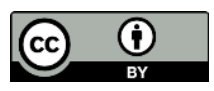

\section{ABSTRACT}

In the recent years, natural fibres have gained greater attention to replace synthetic fibres in producing environmentally friendly green products. These are currently considered as one of the most promising areas of scientific and technological development due to strong global demand for creating a resource circulating society. Rice is one of the largest crops in the world. Sri Lanka being an agricultural country holds twentieth position in the worldwide rice production with 2.4 and 3.9 million metric tons in the years 2017 and 2018 respectively. However, a large amount of rice straw is generated per annum as a by-product of rice production in the country. Even though rice straw is utilized in various ways, there is a possibility for a value addition by extracting its constituents such as cellulose fibres from this underutilized waste material. In this work, cellulose fibres were extracted from locally available rice straw varieties via a series of chemical treatments. Technically modified variety BG352 and traditional variety Murunkan were used for this purpose. The material obtained after chemical treatment was carefully characterized and its chemical composition was determined. Fourier transform Infrared (FTIR) spectroscopy and X-ray diffraction (XRD) analyses showed the progressive and complete removal of non-cellulosic constituents from the rice straw. Morphological investigation was performed using scanning electron microscopy (SEM). Thermal stability of the fibres was investigated using thermogravimetric analysis (TGA). The results showed around 26 and 33 percent cellulose fibres were extracted from rice straw varieties BG352 and Murunkan respectively.

*Corresponding author : banduamp@gmail.com 


\section{INTRODUCTION}

Natural fibres are renewable sources and can be rehabilitated by nature and human ingenuity. These natural fibres play a key role in the emerging green economy. Cellulose, a linear biopolymer is present naturally in all plants. It is a massive source for environmentally friendly and biocompatible products (Fan et al., 2013). Rice straw is considered as an agricultural crop residue which is rich in lignocellulosic materials. Cellulose is the principal constituent of lignocelluloses which has a long chain polysaccharide structure made of $\beta(1,4)$ linked glucose units. The chemical formula of the organic proportions of rice straw is $\mathrm{C}_{6} \mathrm{H}_{9.63} \mathrm{O}_{4.57} \mathrm{~N}_{0.11} \mathrm{~S}_{0.02}$ which is very close to the chemical formula of cellulose monomer $\left(\mathrm{C}_{6} \mathrm{H}_{10} \mathrm{O}_{5}\right)$ (Reddy and Yang, 2006).

Paddy is cultivated as a wetland crop in almost all parts of the country, except at very high altitudes. There are two cultivation seasons in Sri Lanka namely, Yala and Maha which are synonymous with two monsoons. Yala season is effective during "South-east monsoon" from

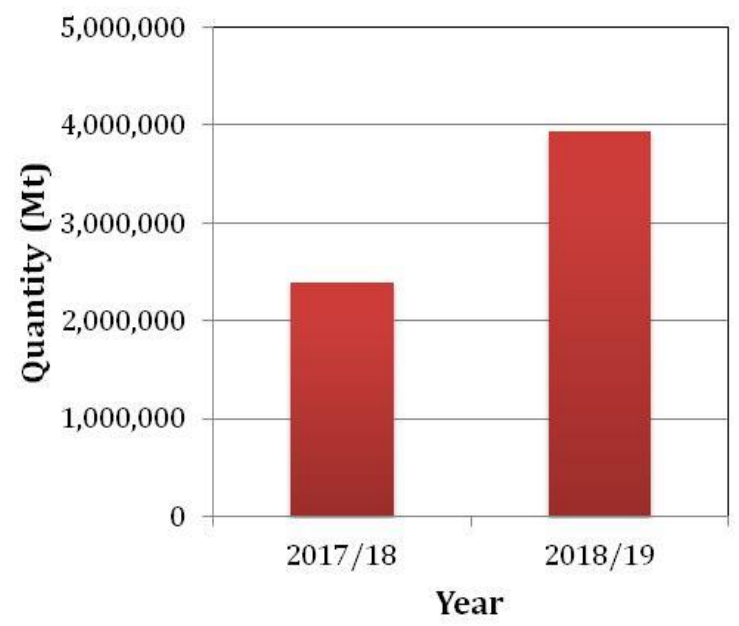

May to end of August whereas Maha season falls during "North-east monsoon" from September to March in the following year.

The total production and land extent under paddy cultivation during Yala and Maha season in the years 2017 and 2018 are shown in Figure 1 (Department of Census and Statistics of Sri Lanka, 2017/2018). Rice straw is a by-product from the paddy cultivation and identified as a residue of agricultural production that is generated in equal or greater quantities than the rice itself. It is projected that the demand for rice will increase at $1.1 \%$ per year. In order to meet this demand, the rice production should grow at the rate of $2.9 \%$ per year. As a result, a significant amount of rice straw will be generated per annum in the country. However, rice straw is considered to be an agricultural waste in developing countries as it cannot be converted into valuable by-products. As we tend to reduce the adverse impact on the environment, the development of effective technologies for utilization of rice straw is both important and significant.

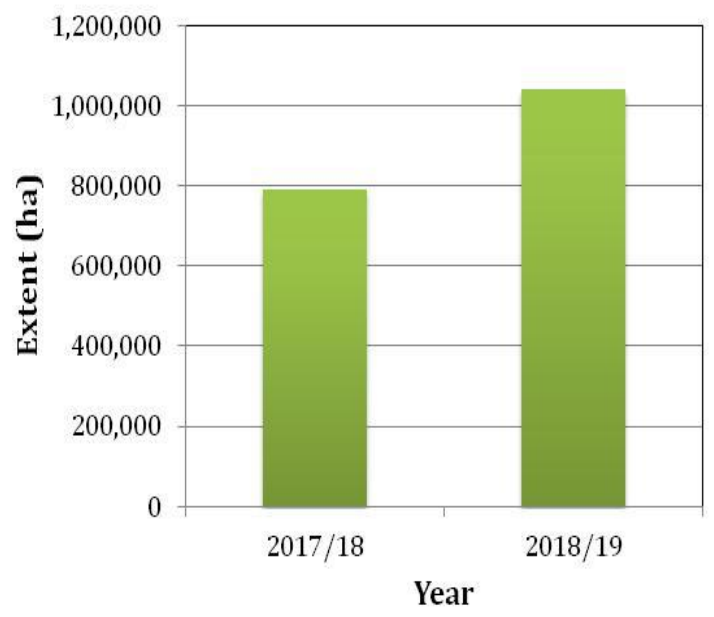

\section{Figure 1. Paddy cultivation in Sri Lanka (a) production quantity and (b) land extent in the years 2017 and 2018.}

Rice straw contains cellulose (22 - 47\%), hemicellolose (19 - 27\%), lignin (5 - 24\%), resin, gum, protein, and mineral compounds. However, effective separation of cellulose fibres from rice straw is difficult due to their pristine crystalline structure and the complex structure of lignin and hemicellulose. Therefore, various pretreatments of rice straw have been developed to split up the structure of cellulose and increase its exposure (Poletto et al., 2013).

In this study, cellulose fibres were extracted from locally available technically modified rice straw variety $B G 352$ and traditional rice straw variety Murunkan via a series of chemical 
treatment methods. The technique adopted includes removal of wax and oil, removal of lignin and removal of hemicellulose and silica from the mentioned rice straw varieties. A comprehensive analysis was performed on untreated and treated rice straw samples to investigate their structural, morphological and thermal properties by using Fourier transform infrared spectroscopy (FTIR), X-ray diffractometry (XRD), scanning electron microscopy (SEM), and thermogravimetric analysis (TGA). Extracting cellulose fibres from rice straw would not only mean an environmentally friendly alternative to synthetic fibres currently in use but will also add value to the rice straw and benefit the farmers economically.

\section{MATERIALS AND METHODS}

\section{Processing of Rice Straw}

Sri Lankan straw from rice varieties $B G 352$ and Murunkan were used in this study. Technically modified rice straw variety $B G 352$ was collected after the 2018 Yala seasonal harvest from Rice Research and Development Institute (RRDI), Bathalagoda and traditional rice straw variety Murunkan was collected after the 2018/2019 Maha seasonal harvest from Provincial Department of Agriculture, Jaffna. Stems of the obtained rice straw were initially cut into 3 to $4 \mathrm{~cm}$ length pieces, then thoroughly washed and dried at $60{ }^{\circ} \mathrm{C}$ for $15 \mathrm{~h}$. Dried rice straw was milled to pass through a 60 mesh aperture size screen.

\section{Cellulose extraction}

Rice straw powder was subjected to a series of chemical extraction and purification processes. Initially, to remove wax and oil, 10 $\mathrm{g}$ of rice straw powder was extracted with $2: 1$, $\mathrm{v} / \mathrm{v}$ toluene/ethanol mixture $(450 \mathrm{~mL})$ at 400

${ }^{\circ} \mathrm{C}$ for $15 \mathrm{~h}$ in a Soxhlet apparatus. Then lignin was removed from dewaxed rice straw powder in $3: 10, \mathrm{v} / \mathrm{v} \mathrm{H}_{2} \mathrm{O}_{2} / \mathrm{CH}_{3} \mathrm{COOH}$ solution at $70{ }^{\circ} \mathrm{C}$ for $3 \mathrm{~h}$ in a thermostatically controlled water bath using $\mathrm{H}_{2} \mathrm{SO}_{4}$ as the catalyst. Finally, the de-lignified rice straw powder was leached with $110 \mathrm{~mL}$ of $5 \% \mathrm{KOH}$ for $24 \mathrm{~h}$ at room temperature then for $2 \mathrm{~h}$ at $90{ }^{\circ} \mathrm{C}$. After the series of chemical treatments, the samples were vacuum filtered and washed with copious amount of water, purified using Barnstead $^{\mathrm{TM}}$ Smart2Pure ${ }^{\mathrm{TM}}$ Water Purification System (Thermo Fisher Scientific, Waltham, MA) until filtrate reached neutral $\mathrm{p}^{\mathrm{H}}$. Finally, oven dried, chemically purified cellulose was collected and stored in desiccators for investigation and characterization (Samarasekara et al., 2015; Nanayakkara et al., 2017a; Nanayakkara et al., 2017b). Three replications were carried out for each compositional analysis, and the average is reported here.

\section{Measurements and Characterization}

Structural, morphological and thermal properties of rice straw and cellulose fibres were studied. FTIR spectra were used to examine the structure of cellulose fibres which were extracted from rice straw after a series of chemical treatments. A Bruker ALPHA spectrometer (Bruker Corporation, Billerica, MA) was used to characterize the spectra of each sample. The untreated and treated rice straw was mixed with $\mathrm{KBr}$ powder $(1: 100$, $\mathrm{w} / \mathrm{w}$ ), and the mixture was compressed into plates for FTIR analysis. FTIR spectra of samples were obtained in the range of 4000 $600 \mathrm{~cm}^{-1}$ in transmittance mode. To achieve the acceptable signal to noise ratio, 24 scans were co-added while the spectra resolution was maintained at $4 \mathrm{~cm}^{-1}$. Structural analysis of the samples was carried out using BRUKER D8 ADVANCE ECO X-ray diffractometer with $\mathrm{Cu} \mathrm{K}_{\alpha}$ radiation $(\lambda=1.5406 \AA)$ at $40 \mathrm{kV}$ and 25 $\mathrm{mA}$. Samples were scanned and recorded the intensity in $2 \theta$ ranged from $5^{\circ}$ to $40^{\circ}$ (step size $=0.02^{\circ}$, scanning rate $=2$ seconds $/$ step). Data refinement and phase analysis were carried out using ICDD database. Scanning electron microscopy analysis (SEM) (EVO 18, Carl Zeiss $\mathrm{AG}, \mathrm{Germany)}$ was performed to determine the structural changes, morphological structure and surface characteristics of the samples. Gold sputter coated samples were examined with an accelerating voltage of 15 $\mathrm{kV}$. Thermal stability of each sample was determined using TGA SDT Q600 simultaneous thermal analyzer (TA instruments, Delaware, USA). Experiments were performed with a heating rate of 10 
${ }^{\circ} \mathrm{C} /$ min from ambient temperature to $800{ }^{\circ} \mathrm{C}$ on rice straw and cellulose under nitrogen environment.

\section{RESULTS AND DISCUSSION}

\section{Chemical composition}

After the series of chemical treatments rice straw variety $B G 352$ yielded $25.35 \pm 0.91$ percent cellulose and Murunkan yielded 33.68 \pm 0.68 percent cellulose. Figure 2 depicts the amount of cellulose, hemicellulose, lignin, wax and ash present in rice straw varieties $B G 352$ and Murunkan. The results show that amount of cellulose fibres present in both the rice straw varieties ranges between $25-34 \%$ which is similar to the previously reported studies (Chen et al., 2011; Nuruddin et al., 2011; Boufi, 2017). However, the observed difference may be due to the difference in rice varieties and soil condition in different locations.

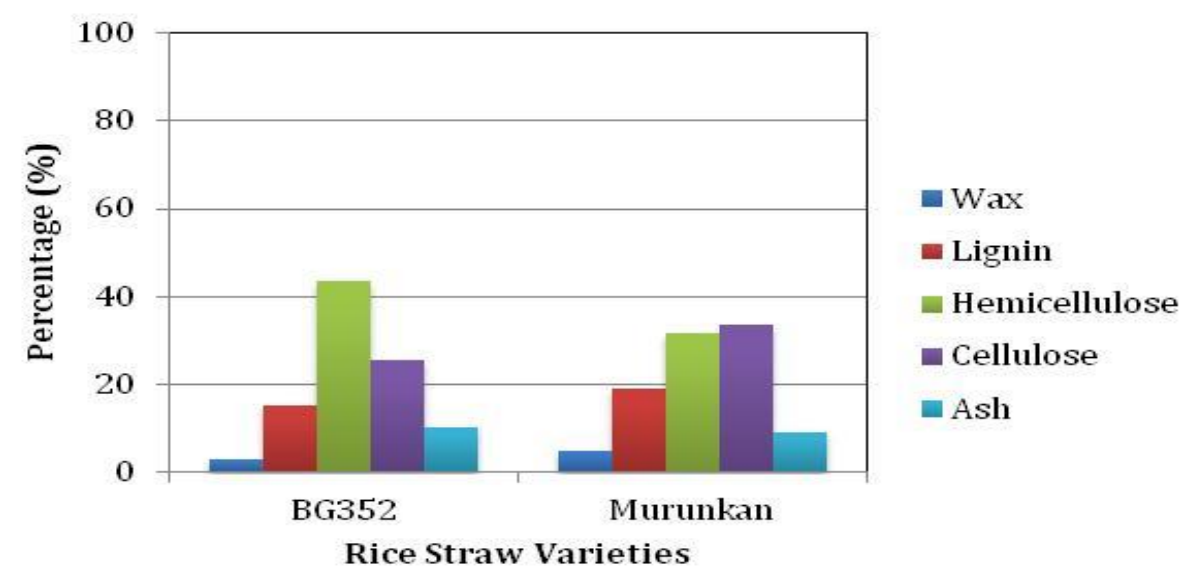

Figure 2. Chemical composition of rice straw varieties BG352 and Murunkan.

\section{Characterization of Untreated and Treated Rice Straw}

\section{Fourier-Transform Infrared Spectroscopy (FTIR) Analysis}

FTIR spectrum of rice straw during the extraction process is shown in Figure 3. After the successful extraction from chemical treatments, the end-product was confirmed as cellulose.

The sequential and complete removal of lignin (1516 $\mathrm{cm}^{-1}$, aromatic skeletal vibrations) in de-lignification and leaching of hemicellulose (1729 $\mathrm{cm}^{-1}$, carbonyl stretching) and silica (796 $\mathrm{cm}^{-1}, \mathrm{Si}^{-}{ }^{-}-\mathrm{Si}$ stretching) in the third step can also be clearly observed. The dominant peaks between 1200 and $900 \mathrm{~cm}^{-1}$ are related to $\mathrm{C}-\mathrm{O}$ stretching bonds. Enhanced peak intensity around $960 \mathrm{~cm}^{-1}$ after chemical treatment implies that a typical structure of cellulose became more dominant compared to the raw materials (Lim et al., 2010).
Figure 4 shows the FTIR spectrum of cellulose fibres extracted from BG352 and Murunkan rice straw varieties. In Figure 4, a strong broad band can be observed in the region of 3700 $3000 \mathrm{~cm}^{-1}$ which is assigned to different $-\mathrm{OH}$ stretching modes and another band in the region of $3000-2800 \mathrm{~cm}^{-1}$ is ascribed to the stretching of asymmetric and symmetric methyl and methylene cellulose groups (Kargbo et al., 2010). The band at around 3445 $\mathrm{cm}^{-1}$ related to $-\mathrm{OH}$ stretching mode is prominent for BG352 than for Murunkan. This probably due to a large number of hydroxyl groups in $B G 352$ which may be associated with an increase in the number of hydrogen bonds formed.

\section{X-Ray Diffraction (XRD) Analysis}

XRD analysis was performed on the untreated and treated rice straw and cellulose fibres to investigate the effect of chemical treatments on the crystalline structure of fibres. 
(a)

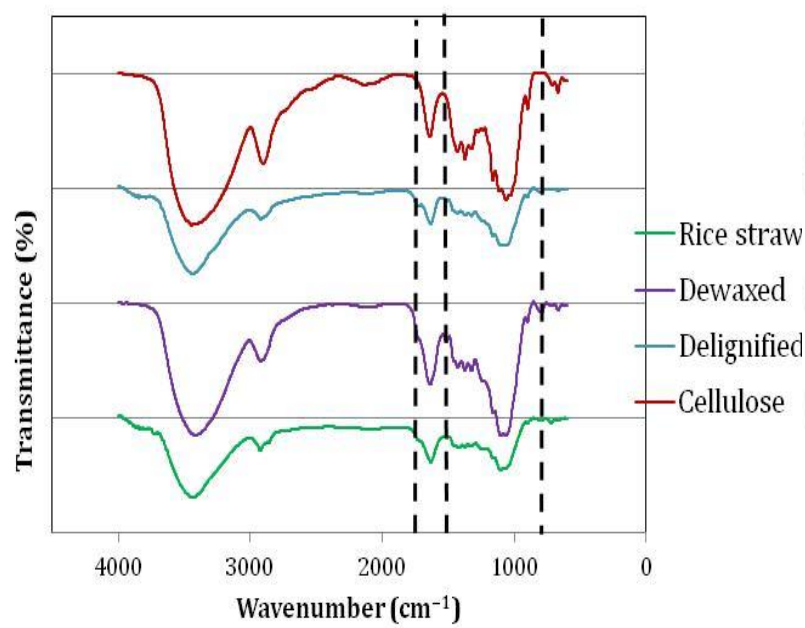

(b)

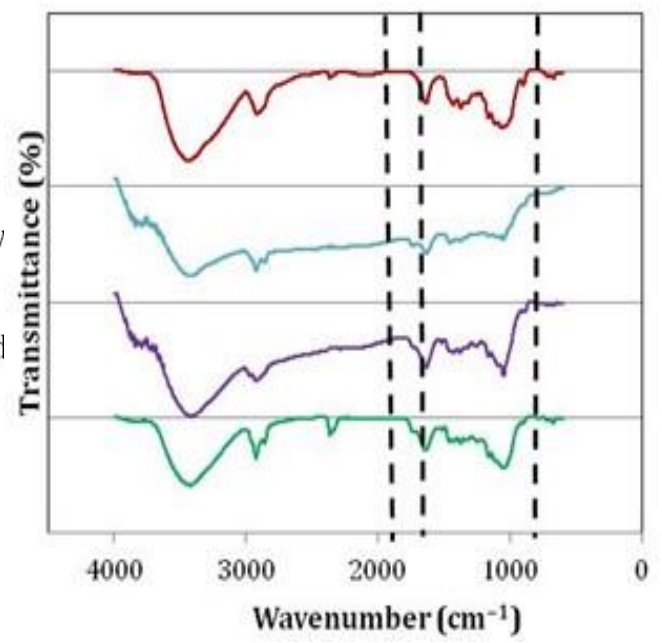

Figure 3. FTIR spectra of rice straw (a) BG352 (b) Murunkan during chemical extraction process

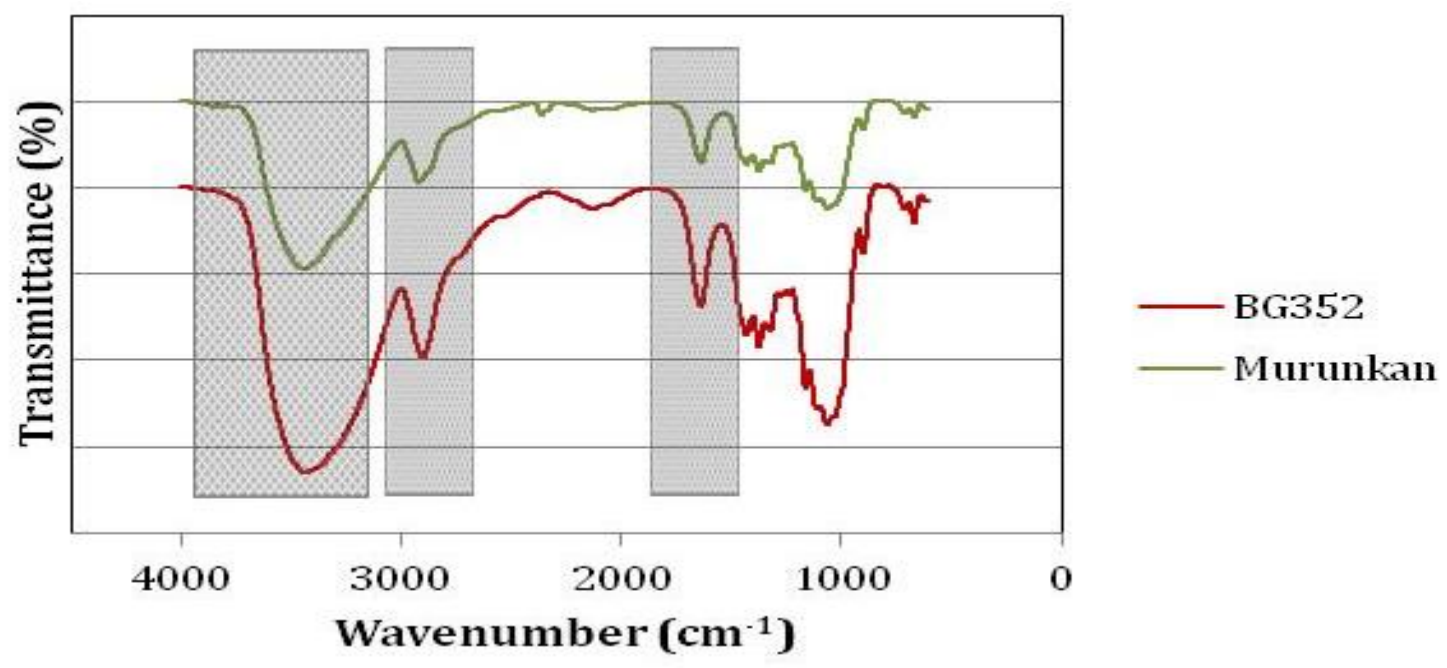

Figure 4. FTIR spectra of cellulose fibres extracted from BG352 and Murunkan

The peak around $22.2^{\circ}$ attribute to the typical crystal lattice of $\mathrm{I}_{\beta}$ which indicates that both rice straw and cellulose exhibit the diffuse characteristics pattern of an amorphous phase. Shoulder peak at $16.4^{\circ}$ and weak peak at $34.7^{\circ}$ in Figure 5 indicates the removal of lignin and hemicellulose from rice straw (Raj et al., 2015; Taylor et al., 2015.; Zheng et al., 2017; Morone et al., 2018). 
(a)

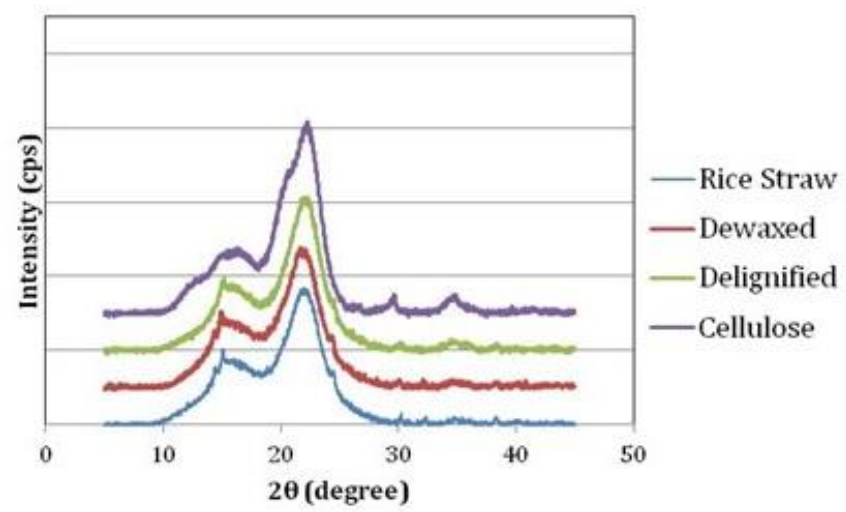

(b)

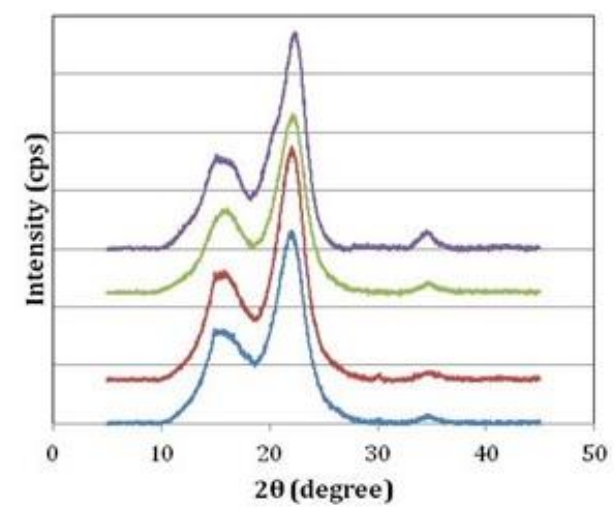

Figure 5. X-ray diffraction patterns of rice straw (a) BG352 (b) Murunkan during chemical extraction process

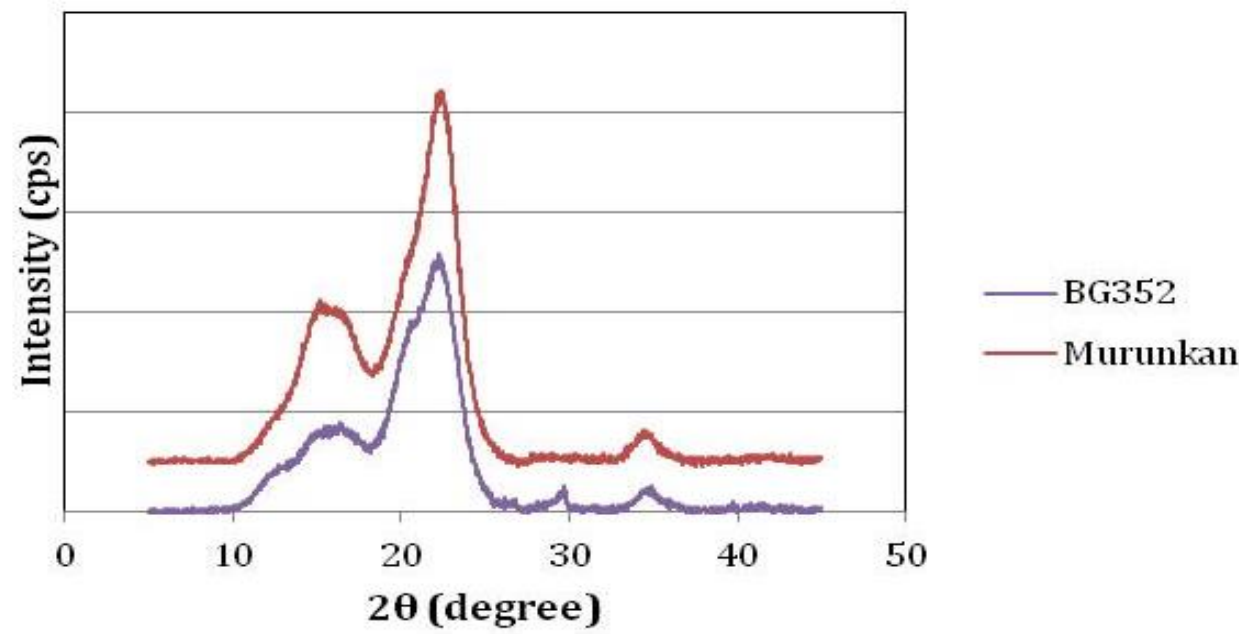

Figure 6. X-ray diffraction pattern of cellulose fibres extracted from BG352 and Murunkan

The series of chemical treatments on rice straw has a great effect on the crystallization of the cellulosic fibres. The sharper diffraction peak around $22.2^{\circ}$ observed in Figure 6 indicates higher degree of crystallinity in the extracted cellulose fibres. Murunkan exhibits sharper peak than $B G 352$. Higher crystallinity observed in the cellulose fibres is associated with higher tensile strength of the fibres.

\section{Scanning Electron Microscopy (SEM) Analysis}

Figure 7 and 8 presents the wide-angle SEM micrographs of the untreated and treated rice straw fibres of BG352 and Murunkan respectively.
After the removal of lignin, the shape of the phytoliths was revealed. Some of them seemed to be dumbbell shape (Figure. 7(c) and 8(c)). Apparently, the shape of phytoliths is not homogeneous within the delignified sample (some appear as a cross shape).

The morphologies of untreated and treated rice straw are observed as greatly different. For untreated rice straw, some parts of dense lignin, hemicelluloses, and ashes surround fibres. However, the surface of treated fibres looks smoother, which is attributed to the removal of amorphous lignin and hemicelluloses therein. The surface morphology of both the rice straw varieties were significantly varied during the 
processing. However, both rice straw varieties (Figure 7 and 8) presents the same type of morphological structures.

\section{Thermogravimetric Analysis (TGA)}

The thermal degradation of cellulose is known to be due to a pyrolytic fragmentation that leads to aromatized entities and finally to a highly cross linked carbon skeleton (Nanayakkara et al., 2018; Samarasekara et al., 2018). Figure 9 shows the thermal degradation behaviour of both the rice straw varieties during the extraction process.

(b)

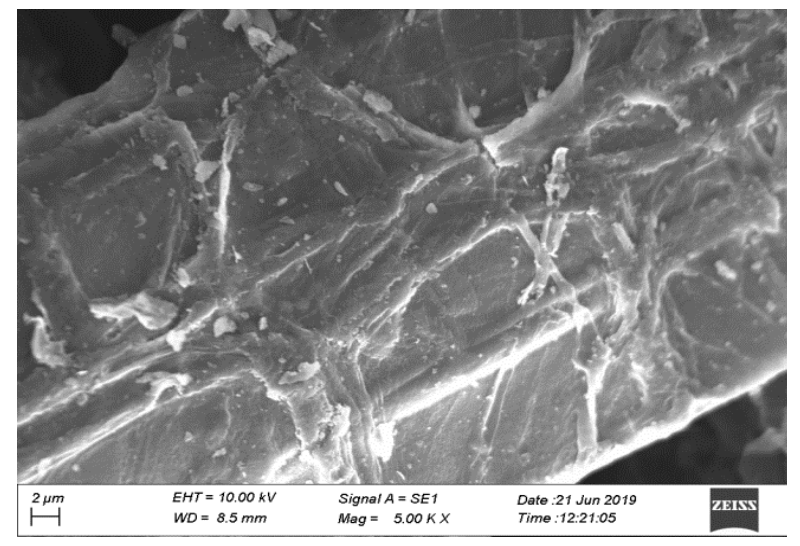

(c)

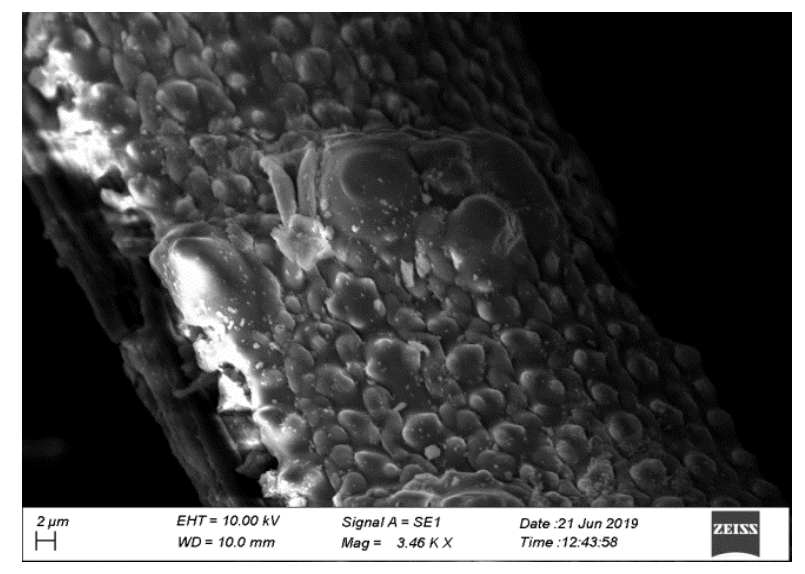

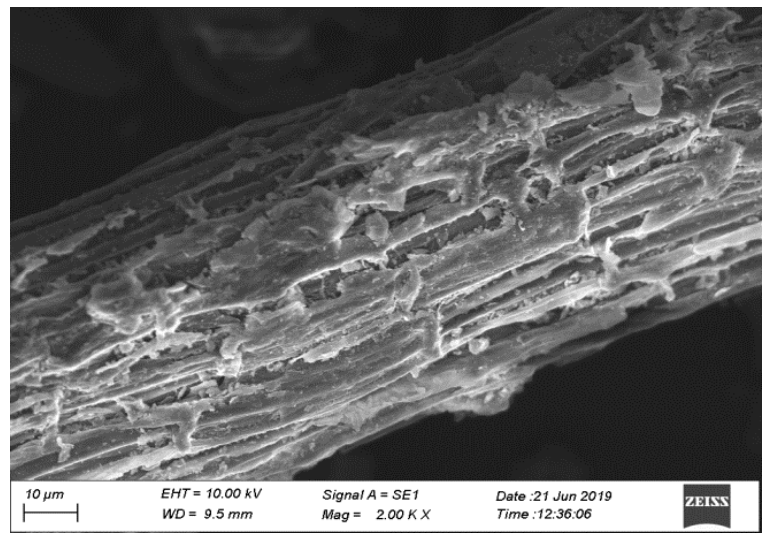

(d)

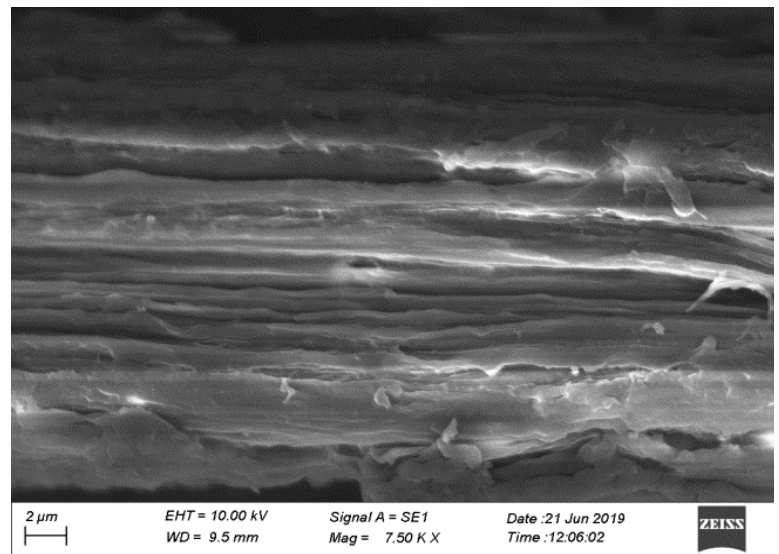

Figure 7. Wide angle SEM micrographs of (a) cleaned, (b) dewaxed, (c) delignified and (d) cellulose fibres derived from rice straw variety $B G 352$

Around $100{ }^{\circ} \mathrm{C}$, a small weight loss is observed. This may be due to the low molecular weight components in the fibres and the evaporation of remained humidity. Another main event in TG curves attributed to hemicelluloses which occurred around $260{ }^{\circ} \mathrm{C}$ and cellulose pyrolysis, which occurred around $310{ }^{\circ} \mathrm{C}$.

Figure 10 shows the thermal degradation behaviour of cellulose fibres extracted from both the rice straw varieties. The resistant increase in cellulose observed is due to the removal of almost all hemicelluloses from rice straw. Further, a significant difference between the contents of the residues remaining after pyrolysis is also observed which indicates that the thermal stability of cellulose is visibly improved. Cellulose fibres extracted from both the rice straw varieties showed similar thermal degradation behaviour. 
(a)

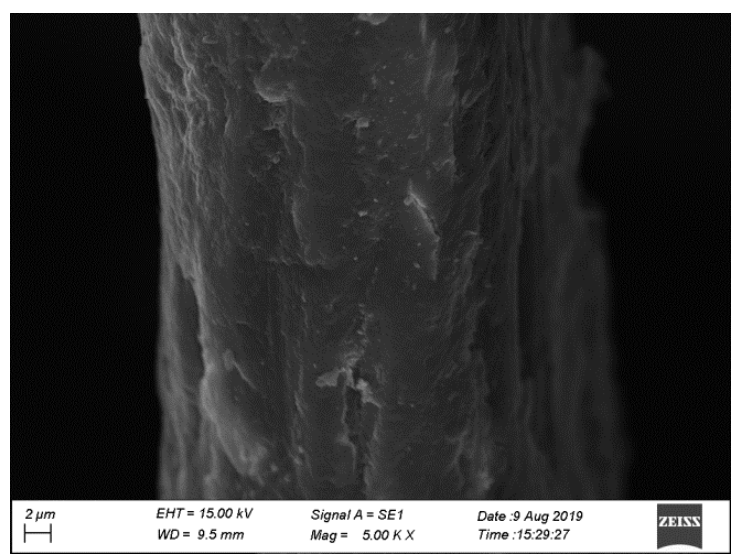

(c)

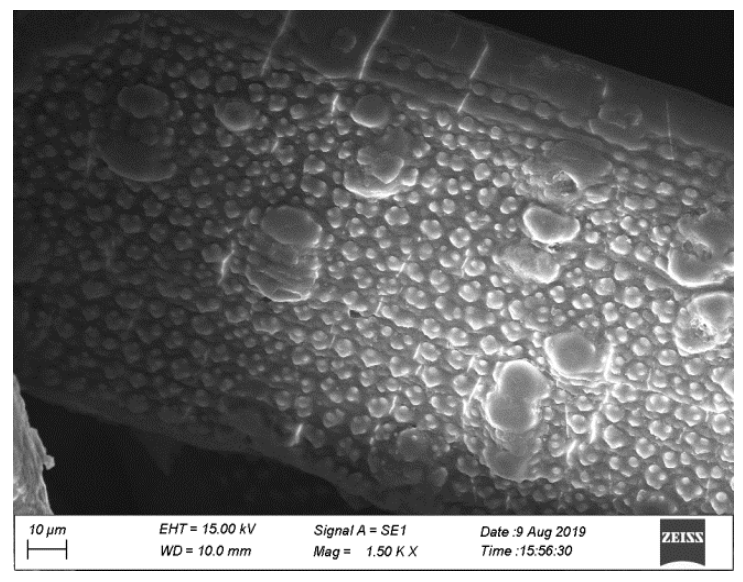

(b)

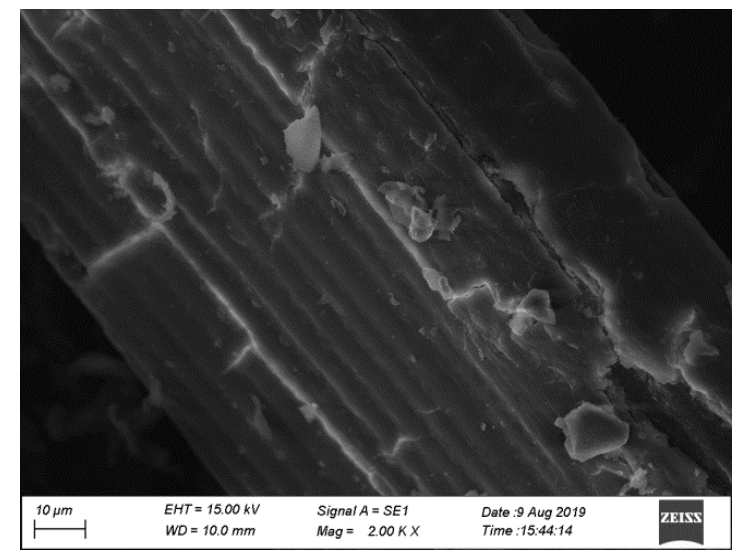

(d)

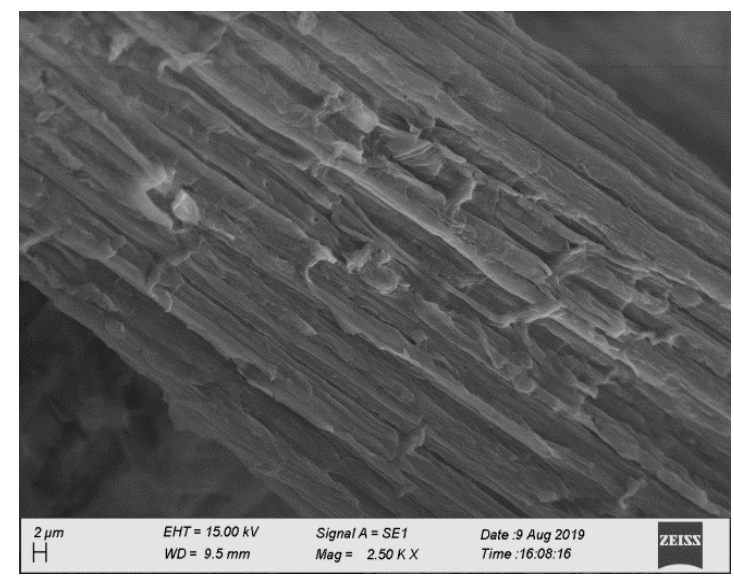

Figure 8. Wide angle SEM micrographs of (a) cleaned, (b) dewaxed, (c) delignified and (d) cellulose fibres derived from rice straw variety Murunkan

(a)

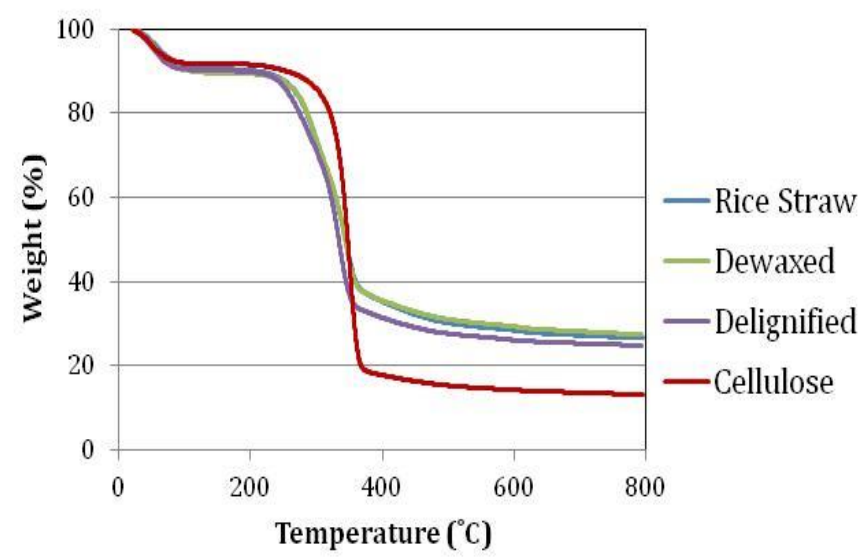

(b)

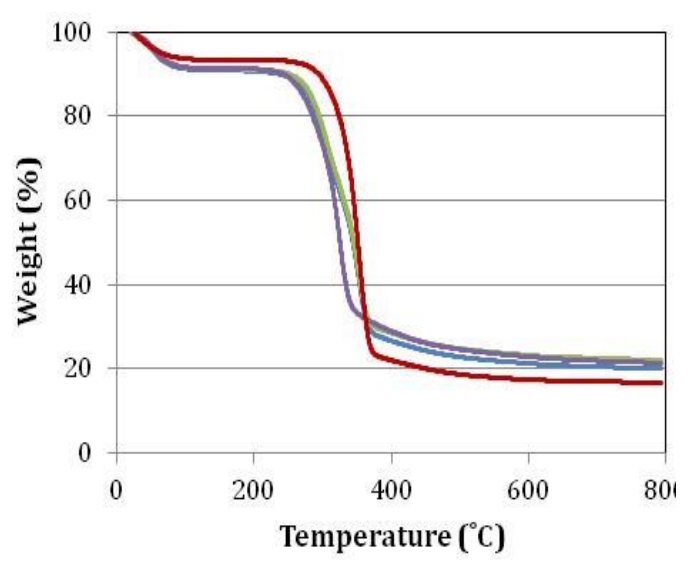

Figure 9. TG curves of rice straw (a) BG352 (b) Murunkan during chemical extraction process 


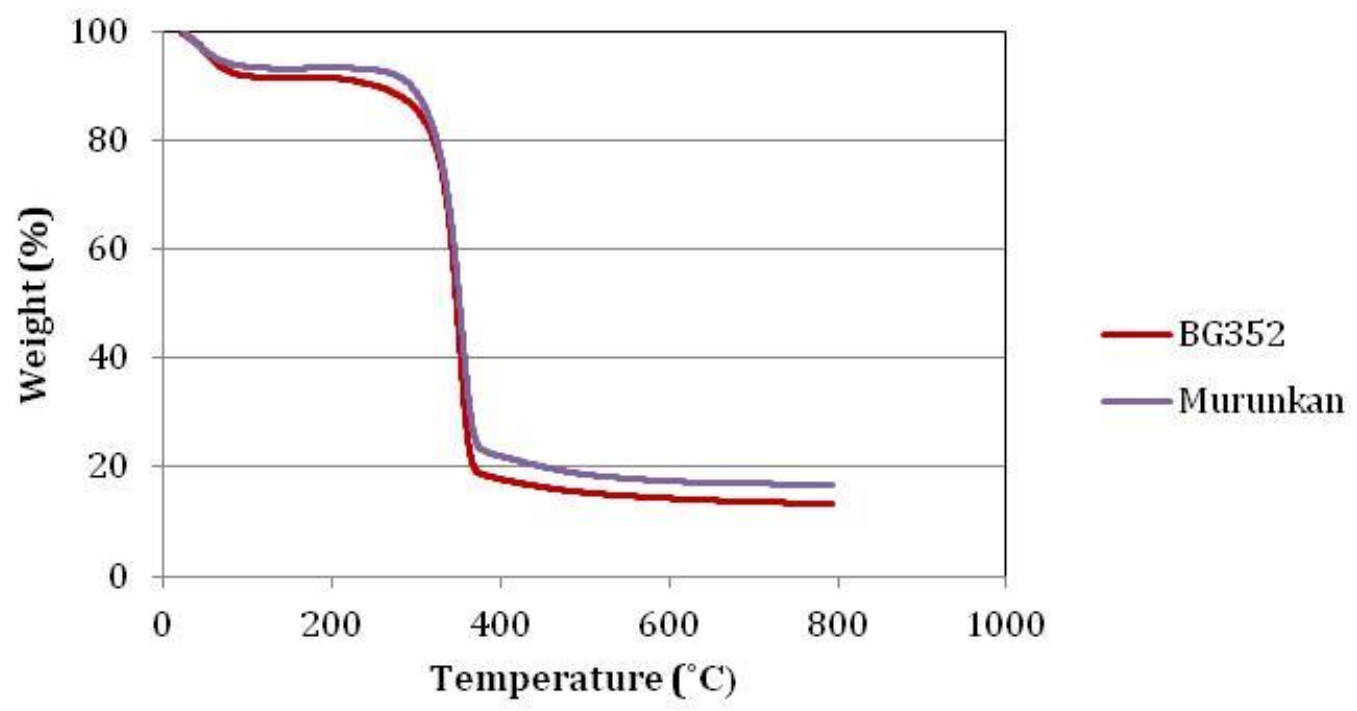

Figure 10. TG curves of cellulose fibres extracted from BG352 and Murunkan

\section{CONCLUSIONS}

Cellulose fibres were successfully extracted via a three-step chemical extraction process from locally available technically modified rice straw variety $B G 352$ and traditional rice straw variety Murunkan. FTIR analysis of rice straw, the images obtained through scanning electron microscope (SEM), and Xray diffraction (XRD) analysis showed the progressive removal of lignin, hemicellulose and silica during the chemical treatments and confirms the final product as cellulose. The study reveals that higher amount of cellulose fibres were extracted from Murunkan (33.68 \pm 0.68 percent) than BG352 (25.35 \pm 0.91 percent). Thermal analysis demonstrated that the thermal properties of the chemically extracted

\section{REFERENCES}

Boufi, S. (2017). Agricultural crop residue as a source for the production of cellulose nanofibrils. Cellulose-Reinforced Nanofibre Composites: Production, Properties and Applications. 6, 129152. cellulose fibres were enhanced. However, cellulose fibres extracted from both the rice straw varieties exhibited similar thermal degradation behaviour. It can be concluded that the extracted cellulose fibres from both the rice straw varieties illustrate better thermal, structural and chemical properties which can be employed in various industrial applications.

\section{ACKNOWLEDGEMENT}

The authors wish to thank M.A.P.C. Gunawardana, S.D. Karunarathna, M.T.M.R. Jayaweera, R.R.P. Perera and H. Amal of Department of Materials Science and Engineering, University of Moratuwa, Sri Lanka for extending their technical support to carry out this research work.

Chen, M., Ma, Y., Xu, Y., Chen, X., Zhang, X. and $\mathrm{Lu}$ C. (2013). Isolation and Characterization of Cellulose Fibres from Rice Straw and its Application in Modified Polypropylene Composites. Polymer-Plastics Technology and Engineering. 52(15), 1566-1573. 
Chen, X., Yu, J., Zhang, Z. and Lu, C. (2011). Study on structure and thermal stability properties of cellulose fibres from rice straw. Carbohydrate polymers. 85(1), 245-250.

Department of Census and Statistics of Sri Lanka (2018). Agriculture and Environment Statistics Division, Paddy Statistics. [on line]. [Accessed on 10.08.2019]. Available at http://www.statistics.gov.lk/agricult ure/Paddy\%20Statistics/PaddyStats. htm

Fan, G., Wang, M., Liao, C., Fang, T., Li, J. and Zhou, R. (2013). Isolation of cellulose from rice straw and its conversion into cellulose acetate catalyzed by phosphotungstic acid. Carbohydrate Polymers, 94(1), 71-76.

Kargbo, F.R., Xing, J. and Zhang, Y. (2010). Property analysis and pretreatment of rice straw for energy use in grain drying: A review. Agriculture and Biology Journal of North America. 1(3), 195-200.

Lim, S.K., Son, T.W., Lee, D.W., Park, B.K. and Cho, K.M. (2001). Novel Regenerated Cellulose Fibres from Rice Straw. Journal of Applied Polymer Science. 82(7), 1705-1708.

Morone, A., Sharma, G., Sharma, A., Chakrabarti, T. and Pandey, R.A. (2018). Evaluation, applicability and optimization of advanced oxidation process for pretreatment of rice straw and its effect on cellulose digestibility. Renewable Energy. 120, 88-97.

Nanayakkara, M.P.A., Pabasara, W.G.A., Samarasekara, A.M.P.B., Amarasinghe, D.A.S. and Karunanayake, L. (2017a). Synthesis and characterization of cellulose from locally available rice straw. In: Proceedings of Moratuwa Engineering Research Conference (MERCon), (29-31 May 2017,
Moratuwa, Sri Lanka), 176-181. DOI: 10.1109/MERCon.2017.7980477

Nanayakkara, M.P.A., Pabasara, W.G.A., Samarasekara, A.M.P.B., Amarasinghe, D.A.S. and Karunanayake, L. (2018). Novel Thermogravimetry Based Analytical Method for Cellulose Yield Prediction of Sri Lankan Rice Straw Varieties. In: Proceedings of Moratuwa Engineering Research Conference (MERCon), (30 May - 1 June 2018, Moratuwa, Sri Lanka), 185-190. DOI: 10.1109/MERCon.2018.8421949

Nanayakkara, M.P.A., Pabasara, W.G.A., Samarasekara, A.M.P.B., Amarasinghe, D.A.S. and Karunanayake, L. (2017b). Extraction and Characterisation of Cellulose Materials from Sri Lankan Agricultural Waste. In: Proceedings of International Forestry and Environment Symposium, (10 - 11 November 2017, Waskaduwa, Sri Lanka), 22, 47.

Nuruddin, M., Chowdhury, A., Haque, S.A., Rahman, M., Farhad, S.F., Jahan, M.S. and Quaiyyum, A. (2011). Extraction and characterization of cellulose microfibrils from agricultural wastes in an integrated biorefinery initiative. Biomaterials, 3, 5-6.

Poletto, M., Pistor, V. and Zattera, A.J. (2013). Structural Characteristics and Thermal Properties of Native Cellulose. Cellulose-fundamental aspects. 2, 45-68.

Raj, T., Kapoor, M., Gaur, R., Christopher, J., Lamba, B. Y., Tuli, D. K. and Kumar, R. (2015). Physical and chemical characterization of various Indian agriculture residues for biofuels production. Energy and Fuel. 29(5), 3111-3118.

Reddy, N. and Yang, Y. (2006). Properties of high-quality long natural cellulose fibres from rice straw. Journal of 
Agricultural and Food Chemistry. 54(21), 8077-8081.

Samarasekara, A.M.P.B. and Kahawita. D.H.N. (2015). Extraction of Cellulose and Hemicellulose from Wood Waste to Produce Biodegradable Composite Material for Engineering Applications. Annual Transactions of Institution of Engineers Sri Lanka, 1(B), 159-165.

Samarasekara, A.M.P.B., Kumara, S.P.D.A., Madhusanka, A.J.S., Amarasinghe, D.A.S. and Karunanayake, L. (2018). Study of Thermal and Mechanical
Properties of Microcrystalline Cellulose and Nanocrystalline Cellulose Based Thermoplastic Material. In: Proceedings of Moratuwa Engineering Research Conference (MERCon), (30 May - 1 June 2018, Moratuwa, Sri Lanka), 465-470. DOI: 10.1109/MERCon.2018.8421906

Zheng, W., Chen, X., Xue, Y., Hu, J., Gao, M.T. and Tsang, Y.F. (2017). The influence of soluble polysaccharides derived from rice straw upon cellulase production by Trichoderma reesei. Process Biochemistry. 61, 130-136. 